\title{
Highly-Efficient Caffeine Recovery from Green Coffee Beans under Ultrasound-Assisted $\mathrm{SC}-\mathrm{CO}_{2}$ Extraction
}

\author{
Janet Menzio, Arianna Binello $\mathbb{D}$, Alessandro Barge $\mathbb{D}$ and Giancarlo Cravotto * $\mathbb{D}$ \\ Dipartimento di Scienza e Tecnologia del Farmaco, University of Turin, Via P. Giuria 9, 10125 Turin, Italy \\ janet.menzio@unito.it (J.M.); arianna.binello@unito.it (A.B.); alessandro.barge@unito.it (A.B.) \\ * Correspondence: giancarlo.cravotto@unito.it; Tel.: +39-011-670-7183; Fax: +39-011-670-7162
}

Received: 2 August 2020; Accepted: 19 August 2020; Published: 1 September 2020

\begin{abstract}
Natural caffeine from decaffeination processes is widely used by pharmaceutical, cosmetic and soft-drink industries. Supercritical $\mathrm{CO}_{2}$ extraction $\left(\mathrm{SFE}-\mathrm{CO}_{2}\right)$ is extensively exploited industrially, and one of its most representative applications is the decaffeination process, which is a greener alternative to the use of organic solvents. Despite its advantages, extraction kinetics are rather slow near the $\mathrm{CO}_{2}$ critical point, meaning that improvements are highly sought after. The effect exerted by a combination of SFE- $\mathrm{CO}_{2}$ and ultrasound (US-SFE- $-\mathrm{CO}_{2}$ ) has been investigated in this preliminary study, with the aim of improving mass transfer and selectivity in the extraction of caffeine from green coffee beans. This hybrid technology can considerably enhance the extraction efficiency and cut down process time. Further studies are in progress to demonstrate the complete decaffeination of green coffee beans of different types and origins.
\end{abstract}

Keywords: caffeine; green coffee beans; supercritical $\mathrm{CO}_{2}$ extraction; ultrasound; hybrid technology

\section{Introduction}

Caffeine is a xanthine alkaloid widely used in beverages (soft or energy drinks), as well as in pharmaceutical and cosmetic preparations [1]. The global caffeine market was valued at US\$ 231.1 million in 2018 and is expected to reach US\$ 349.2 million by 2027 expanding at a CAGR (Compound Annual Growth Rate) of 4.7\% during the forecast from 2019 to 2027 [2]. This rising demand boosts the global caffeine market. Besides production via chemical synthesis, there is an urgent need to increase caffeine production via isolation from natural sources, the principle of which is coffee beans [3,4]. The decaffeination of green coffee beans commonly involves several steps, such as steaming, extraction, drying and caffeine recovery [4-6]. Growing concerns as to the use of organic solvents has stimulated the development of greener techniques for more sustainable and efficient caffeine extraction. Of the alternative green processes available, supercritical $\mathrm{CO}_{2}$ extraction $\left(\mathrm{SFE}-\mathrm{CO}_{2}\right)$ can be considered the technique of choice for decaffeination and the recovery of high-value lipophilic compounds from natural matrices [7,8]. A molecular dynamics simulation study demonstrated that, unlike extraction in water, $\mathrm{SFE}-\mathrm{CO}_{2}$ does not favour the aggregation of the caffeine obtained, thus facilitating subsequent purification steps [9]. The aim of extracting $97 \%$ caffeine from both Arabica and Robusta green coffee beans has been achieved by this technology in $11.5 \mathrm{~h}$ and $22 \mathrm{~h}$, respectively, at $90{ }^{\circ} \mathrm{C}$ and 247 bar [10]. The efficiency of SFE- $\mathrm{CO}_{2}$ can be further improved by the addition of a co-solvent, such as ethanol, in order to enhance the polarity of the system [11]. SFE is generally characterised by slow kinetics, meaning that mass-transfer intensification would be a welcome means to improve diffusion. Ultrasound-assisted extraction (UAE) is extremely beneficial, in this sense, thanks to the enhanced mass transfer that occurs under acoustic cavitation [12,13]. Farouk \& Hasan [14] have carried out a study using a high-order numerical scheme, and the data seem to confirm that the kinetics of the SFE process are significantly accelerated by cavitational effects. Higher extraction 
yields and shorter extraction times can therefore be achieved when $\mathrm{SFE}-\mathrm{CO}_{2}$ processes are assisted by ultrasound (US) [15]. Currently, US-SFE- $\mathrm{CO}_{2}$ extractors are mainly available only on lab and pilot scales, and there is a distinct lack of industrial-scale data [16]. Extensive analysis on the synergistic effect of US with SFE- $\mathrm{CO}_{2}$ have been summarized by Dassoff \& Li, [17], namely micro- and macro-mixing, mechanical effects on the cell wall that enhance both convective mass transfer as well as internal diffusivity. Under $\mathrm{CO}_{2}$ pressure the oxidative degradations that may occur under sonication are negligible. A pilot-scale process using an innovative US-SFE- $\mathrm{CO}_{2}$ system has been proposed for oil extraction from different vegetal matrices [18].

The aim of this work is to evaluate the effectiveness of ultrasound assistance in the extraction of caffeine from green coffee beans using $\mathrm{SFE}-\mathrm{CO}_{2}$. This preliminary investigation should provide useful data to facilitate a drastic reduction in extraction time. The scalability of this hybrid technology for decaffeination will require further engineering studies. In this work, an SFE unit, equipped with a tightly fixed sonotrode with an immersion horn, has been used under sonication and silent conditions. Extract analysis was carried out using ultra-performance liquid chromatography-tandem mass spectrometry (UPLC-MS-MS).

\section{Materials and Methods}

\subsection{Coffee Sample and Chemicals}

Green coffee beans (Arabica, Brazil), that had been previously hydrated to reach 31\% moisture, were kindly provided by Lavazza S.p.A (Settimo Torinese, Turin, Italy) and stored in vacuum bags. The densities of the dry coffee $\left(710 \mathrm{~kg} / \mathrm{m}^{3}\right)$ and wet coffee $\left(550 \mathrm{~kg} / \mathrm{m}^{3}\right)$ were calculated in order to select the most appropriate volume for the experiments. The more suitable amount used for the experiments was $185 \mathrm{~g}$ of wet coffee (water $31 \%$ ) corresponding at $144.5 \mathrm{~g}$ of dry coffee (water $11 \%$ ). A remarkable swelling of green coffee beans in water was observed during the humidification process. A caffeine standard (99.7\%) was purchased from Alfa Aesar (Karlsruhe, Germany). Acetonitrile, trifluoroacetic acid (TFA) and magnesium oxide (MgO) were obtained from Merck KGaA (Darmstadt, Germany).

\subsection{Supercritical $\mathrm{CO}_{2}$ Extraction ( $\mathrm{SFE}-\mathrm{CO}_{2}$ ) and Ultrasound-Assisted Supercritical $\mathrm{CO}_{2}$ Extraction $\left(\mathrm{US}-\mathrm{SFE}-\mathrm{CO}_{2}\right.$ )}

The SFE- $\mathrm{CO}_{2}$ and US-SFE- $\mathrm{CO}_{2}$ of caffeine from green coffee beans were performed in a prototype designed and assembled by Weber Ultrasonics GA (Karlsbad, Germany) and FeyeCon B.V. (Weesp, The Netherlands). The prototype was equipped with a system that circulated fluid through the extraction chamber (11-13 $\mathrm{kg} \mathrm{h}^{-1}$ of $\mathrm{CO}_{2}$ ), an insulating jacket and an immersion titanium horn for US-assisted procedures.

For SFE- $\mathrm{CO}_{2}$, green coffee beans were weighed $(185 \mathrm{~g})$ and placed into the $1 \mathrm{~L}$-capacity extraction vessel. Different pressure and temperature conditions were tested. Moreover, SFE- $\mathrm{CO}_{2}$ efficiency was compared to that of the extraction with liquid $\mathrm{CO}_{2}\left(\mathrm{LE}-\mathrm{CO}_{2}\right)$, with pressure and temperature being set under the critical point. Similar conditions used in SFE- $\mathrm{CO}_{2}$ were applied for US-SFE- $\mathrm{CO}_{2}$. US assistance was obtained thanks to a probe system equipped with a titanium horn $(40 \mathrm{kHz} ; \mathrm{P}=90 \% \mathrm{~W})$ that was placed in the extraction vessel. To avoid localized sample overheating, the horn was set to operate $5 \mathrm{~min}$ on and $2 \mathrm{~min}$ off for the whole extraction time (see Table 1 for tested conditions).

Each procedure was repeated three times to verify extraction method reproducibility, and all of the processes provided an aqueous extract that was subsequently freeze dried (Freeze drier LyoQuest-85, Telstar, Legnano, Italy). A $0.5 \mathrm{mg} / \mathrm{mL}$ aqueous solution of each obtained sample was prepared and transferred into a vial for UPLC-MS/MS analysis. Results are expressed as mean data \pm standard deviation (SD). 
Table 1. Experimental conditions for caffeine extraction from Arabica green coffee beans and caffeine determination using UPLC-MS/MS analyses. Reported data are the mean of two experiments.

\begin{tabular}{|c|c|c|c|c|c|c|c|c|c|}
\hline Entry & Sample (g) & $\begin{array}{c}\text { Temperature } \\
\left({ }^{\circ} \mathrm{C}\right)\end{array}$ & $\begin{array}{l}\text { Pressure } \\
\text { (bar) }\end{array}$ & $\begin{array}{l}\text { Extraction } \\
\text { Method }\end{array}$ & $\begin{array}{c}\text { Total } \\
\text { Caffeine } \\
(\mathrm{mg})\end{array}$ & $\begin{array}{c}\text { Extract } \\
\text { Caffeine \% }\end{array}$ & $\begin{array}{c}\text { Caffeine } \\
\text { mg/g Coffee } \\
\text { Beans }\end{array}$ & Decaffein. \% & Time (h) \\
\hline 1 & 185 & 75 & 250 & $1^{\mathrm{a}}$ & $155.1 \pm 10.6$ & $83.2 \pm 5.9$ & $0.838 \pm 0.06$ & $8.86 \pm 0.61$ & 1 \\
\hline 2 & 185 & 40 & 250 & $1^{a}$ & $59.2 \pm 4.5$ & $76.2 \pm 5.8$ & $0.320 \pm 0.02$ & $3.38 \pm 0.26$ & 1 \\
\hline 3 & 185 & 20 & 70 & $2^{b}$ & $26.3 \pm 3.8$ & $80.2 \pm 11.6$ & $0.142 \pm 0.02$ & $1.50 \pm 0.21$ & 1 \\
\hline 4 & 185 & 75 & 250 & $3^{c}$ & $318.3 \pm 19.7$ & $90.1 \pm 5.6$ & $1.72 \pm 0.1$ & $18.19 \pm 1.1$ & 1 \\
\hline 5 & 185 & 40 & 250 & $3^{c}$ & $126.5 \pm 10.4$ & $83.9 \pm 6.9$ & $0.684 \pm 0.06$ & $7.23 \pm 0.6$ & 1 \\
\hline 6 & 185 & 75 & 125 & $3^{c}$ & $279.8 \pm 15.8$ & $74.1 \pm 4.2$ & $1.51 \pm 0.08$ & $15.98 \pm 0.9$ & 1 \\
\hline 7 & 50 & 75 & 250 & $3^{c}$ & $148.5 \pm 9.3$ & $69.0 \pm 4.3$ & $2.97 \pm 0.18$ & $31.4 \pm 1.9$ & 1 \\
\hline 8 & 185 & 75 & 250 & $3^{c}$ & $673.8 \pm 25.8$ & $87.3 \pm 3.3$ & $3.64 \pm 0.12$ & $38.5 \pm 1.4$ & 2 \\
\hline 9 & 185 & 75 & 250 & $3^{c}$ & $906.5 \pm 30.6$ & $91.6 \pm 3.1$ & $6.04 \pm 0.2$ & $51.8 \pm 1.8$ & 3 \\
\hline 10 & 185 & 75 & 250 & $3^{c}$ & $1104.3 \pm 40.1$ & $93.4 \pm 3.3$ & $5.97 \pm 0.2$ & $63.1 \pm 2.3$ & 4 \\
\hline
\end{tabular}

\subsection{Conventional Caffeine Extraction}

In order to evaluate the total caffeine content in the green coffee beans used for the experiments, a conventional extraction was performed. Briefly, $100 \mathrm{~mL}$ of water and $4 \mathrm{~g}$ of $\mathrm{MgO}$ were added to $1 \mathrm{~g}$ of ground green coffee beans, and the obtained mixture was stirred for 1 hour at $90^{\circ} \mathrm{C}$, then filtered. The filtrate was brought to $250 \mathrm{~mL}$ with water and placed into a $250 \mathrm{~mL}$ graduated flask, and this solution was used for caffeine quantification via UPLC-MS/MS. The procedure was repeated three times to evaluate extraction-yield reproducibility. The efficiency of this conventional extraction method was confirmed by re-extracting, under the same conditions, the residual coffee sample derived from the filtration procedure.

\subsection{Qualitative and Quantitative Analyses}

Analyses were performed using a UPLC-MS/MS system (Acquity TQD LC/MS/MS System, Waters Corporation, Milford, MA, USA), equipped with a C-18 column (BEH C-18, $2.1 \times 50 \mathrm{~mm}$, $1.7 \mu \mathrm{m})$. Isocratic elution was carried out at $50{ }^{\circ} \mathrm{C}$ with $90: 10 v / v$ of water $(0.1 \%$ TFA)/acetonitrile (0.1\%TFA). The flow rate was set at $0.4 \mathrm{~mL} \mathrm{~min}^{-1}$.

For determination, we operated in atmospheric-pressure chemical ionization (APCI + ) mode, following the transitions $\mathrm{m} / \mathrm{z}=195->138$ (quantification) and $\mathrm{m} / \mathrm{z}=195->110$ (qualitative confirmation of the peak), using $26 \mathrm{eV}$ as the collision energy. The calibration curve of the UPLC-MS/MS method was determined using aqueous caffeine standard solutions (from 0.01 to $1 \mathrm{mg} / \mathrm{mL}$ ); a linear regression with $\mathrm{R}^{2}=0.9994$ was obtained using Waters QuanLynx software (LOD $0.005 \mathrm{mg} / \mathrm{mL}$, LOQ $0.01 \mathrm{mg} / \mathrm{mL}$ ).

\section{Results and Discussion}

\subsection{SFE-CO $\mathrm{CO}_{2}, \mathrm{LE}-\mathrm{CO}_{2}$ and US-SFE-CO $\mathrm{C}_{2}$ of Green Coffee Beans}

Computational simulation studies on caffeine extraction from a fixed bed of coffee beans indicate that acoustic waves could significantly accelerate the kinetics of SFE thanks to their physical/mechanical effects on the treated vegetal matrix, therefore leading to an improvement of extraction rate and yield [9]. To the best of our knowledge, effective experimental works involving the hybrid technology US-SFE- $\mathrm{CO}_{2}$ in coffee decaffeination have not been reported so far.

This study aims to evaluate the possibility of using the effect of cavitation to improve the SFE-CO of caffeine from Arabica green coffee beans, in terms of reducing the process time and temperature and also enriching extracts.

Several experiments were carried out under US assistance, and silent conditions, using samples with $31 \%$ moisture. It was decided that all tests would be performed in a relatively short process time $(1 \mathrm{~h})$, although that does not lead to exhaustive caffeine extraction, which is an operation that usually 
requires several hours [10]. Nevertheless, under these conditions, a preliminary assessment of the beneficial effects of US-SFE- $\mathrm{CO}_{2}$ was performed. The highest extraction temperature was set at $75^{\circ} \mathrm{C}$.

Different conditions were applied in the first runs using SFE- $\mathrm{CO}_{2}$ alone. The extraction vessel was filled to about $80 \%$ maximum volume with $185 \mathrm{~g}$ of matrix (Table 1, entry one and two). For the sake of comparison, $\mathrm{LE}-\mathrm{CO}_{2}$ (Table 1, entry three) was also performed. US-SFE- $\mathrm{CO}_{2}$ was then initially carried out under the same experimental conditions as in $\mathrm{SFE}-\mathrm{CO}_{2}$ (Table 1, entries four and five). Subsequently, the influence of both lower pressure and sample amount were tested at the highest temperature (Table 1, entries six and seven, respectively).

Qualitative and quantitative analyses were performed using UPLC-MS/MS on the freeze-dried extracts in order to evaluate caffeine extraction yields and sample enrichment. Data (Table 1) were compared to the mean caffeine content in coffee $(9.46 \mathrm{mg} / \mathrm{g})$ obtained from exhaustive conventional water extraction in order to calculate the decaffeination percentage achieved.

Results clearly show that temperature plays a crucial role in extractions carried out under silent conditions (entries one, two and three). Although a poor extraction yield was observed when $\mathrm{CO}_{2}$ was used in liquid conditions, extract purity was relatively high. Under supercritical conditions, yields were found to be directly correlated to increasing temperature and also gave better extract purity, which reached $83.2 \%$ at $75{ }^{\circ} \mathrm{C}$. Despite reports by Machmudah et al. [8] on the solubility of caffeine in $\mathrm{SC}-\mathrm{CO}_{2}$ at pressures above $19 \mathrm{MPa} / 190$ bar, caffeine solubility increases with increasing temperature, which however is in agreement with Saldana et al. [19].

\subsection{US-SFE- $\mathrm{CO}_{2}$ Efficiency}

By comparing entries one and four, both carried out at $75{ }^{\circ} \mathrm{C}$ and $250 \mathrm{bar}$, it is possible to see that caffeine amount and decaffeination percentages were doubled thanks to the cavitation phenomenon. A better result if compared with data reported by Farouk \& Hasan [14], that showed an enhancement of caffeine extraction yield by around $15 \%-25 \%$. Moreover, our results evidenced the effect of sonication on extract purity $(90.1 \%)$. A similar trend can be observed when comparing entries two and five, which were performed at low temperature $\left(40{ }^{\circ} \mathrm{C}\right)$. These preliminary results demonstrate how US is a potential, efficient way of enhancing mass transfer processes in SFE. The use of US enabled higher yields in a shorter time, in agreement with Rodríguez et al. [20] who observed $109 \%-150 \%$ improvement at 30 min comparing SFE- $\mathrm{CO}_{2}$ and US-SFE- $\mathrm{CO}_{2}$ in cocoa butter extraction.

Lower pressure (125 vs. 250 bar) and lower filling volume (50 g vs. 185) (entry six and seven, respectively) confirmed the pivotal role of $\mathrm{CO}_{2}$ pressure [21] as well as a better sound wave diffusion in the sonication cone of the horn tip. Entry four gave up to $90.1 \%$ of caffeine in the extract and $18.19 \%$ of sample decaffeination. The obtained results showed that the caffeine extraction yield was lower, by about $12 \%$, at 125 bar (entry six). US intensity must be strong enough to induce vibrational effects [22] when a probe system equipped with a titanium horn $(40 \mathrm{kHz} ; \mathrm{P}=90 \% \mathrm{~W})$ was employed. In the case of a lower sample amount in the extraction vessel (entry seven) higher mass extraction was achieved; a caffeine amount of $2.97 \mathrm{mg}$ per gram of coffee bean was raised, whereas $1.72 \mathrm{mg} / \mathrm{g}$ was obtained in entry four. These values reveal that there is an increase in the sonication effect when less vessel volume was occupied by the matrix, thus allowing for better propagation of acoustic waves at lower pressure. Anyway, under these conditions, extracts showed 20\% less of caffeine content. This, as observed by field emission scanning electron microscopy by Balachandran et al. [23] that reported $200 \mu \mathrm{m}$ surface damage in ginger particles, is more likely due to stronger cell-wall rupture and then to higher metabolite release, which results in our case in a lower selectivity for caffeine.

In order to evaluate decaffeination kinetics, the best extraction conditions (entry four) were used for longer times, 2, 3, $4 \mathrm{~h}$ (entries eight, nine, ten). It was found that longer extraction times gave a higher decaffeination percentage, up to $63.1 \%$ after $4 \mathrm{~h}$, with no significant influence on extract purity. 


\section{Conclusions}

In this preliminary study on caffeine extraction from Arabica green coffee beans, $\mathrm{SFE}-\mathrm{CO}_{2}$ and US-SFE- $\mathrm{CO}_{2}$ have been compared under different experimental conditions. Results show that, in $1 \mathrm{~h}$ of extraction time, the effect of acoustic waves can lead to a doubling of caffeine extraction yield and around $10 \%$ higher extract purity. The best experimental parameters (US-SFE- $\mathrm{CO}_{2}, 75^{\circ} \mathrm{C}, 250$ bar, $185 \mathrm{~g}$ of sample amount) were also tested at longer process times, and thus $63.1 \%$ decaffeination was achieved in $4 \mathrm{~h}$. These experimental data lay the foundation for further studies into caffeine US-SFE- $\mathrm{CO}_{2}$ from coffee beans, both as an improvement of the decaffeination process in the coffee industry, and as an effective technique to produce purer extracts in shorter times for industrial use.

Author Contributions: Conceptualization, A.B. (Arianna Binello) and G.C.; methodology, J.M. and G.C.; validation, A.B. (Alessandro Barge); formal analysis A.B. (Alessandro Barge); investigation, J.M.; data curation, J.M.; writing—original draft preparation, J.M. and A.B. (Arianna Binello); writing—review and editing G.C.; supervision, G.C. All authors have read and agreed to the published version of the manuscript.

Funding: The Manunet Transnational Call 2019 Project “Ultraclean” is warmly acknowledged.

Acknowledgments: Inga Grigaliunaite (FeyeCon, Weesp-Holand) is warmly acknowledged for the valuable technical assistance.

Conflicts of Interest: The authors declare no conflict of interest.

\section{References}

1. Vuong, Q.V.; Roach, P.D. Caffeine in green tea: Its removal and isolation. Sep. Purif. Rev. 2014, 43, 155-174. [CrossRef]

2. Global \$350M Caffeine Market Outlook and Forecast 2020-2027. Available online: https: //www.globenewswire.com/news-release/2020/03/02/1993360/0/en/Global-350M-Caffeine-MarketOutlook-and-Forecast-2020-2027.html (accessed on 1 August 2020).

3. Shinde, R.R.; Shinde, N.H. Extraction of caffeine from coffee and preparation of anacin drug. Int. J. Eng. Res. Technol. 2017, 10, 236-239.

4. Andreeva, E.Y.; Dmitrienko, S.G.; Zolotov, Y.A. Methylxanthines: Properties and determination in various objects. Russ. Chem. Rev. 2012, 81, 397-414. [CrossRef]

5. Belay, A.; Ture, K.; Redi, M.; Asfaw, A. Measurement of caffeine in coffee beans with UV/vis spectrometer. Food Chem. 2008, 108, 310-315. [CrossRef]

6. Kumar, V.; Ravishankar, G.A. Current trends in producing low levels of caffeine in coffee berry and processed coffee powder. Food Rev. Int. 2009, 25, 175-197. [CrossRef]

7. Hasan, N.; Farouk, B. Mass transfer enhancement in supercritical fluid extraction by acoustic waves. J. Supercrit. Fluids 2013, 80, 60-70. [CrossRef]

8. Machmudah, S.; Kitada, K.; Sasaki, M.; Goto, M.; Munemasa, J.; Yamagata, M. Simultaneous Extraction and Separation Process for Coffee Beans with Supercritical $\mathrm{CO}_{2}$ and Water. Ind. Eng. Chem. Res. 2011, 50, 2227-2235. [CrossRef]

9. Reddy, V.; Saharay, M. Solubility of Caffeine in Supercritical $\mathrm{CO}_{2}$ : A Molecular Dynamics Simulation Study. J. Phys. Chem. B 2019, 123, 9685-9691. [CrossRef]

10. Marco, I.D.; Riemma, S.; Iannone, R. Life cycle assessment of supercritical $\mathrm{CO}_{2}$ extraction of caffeine from coffee beans. J. Supercrit. Fluid 2018, 133, 393-400. [CrossRef]

11. Araújo, M.N.; Paladonai, A.Q.; Azevedo, L.; Hamerski, F.; Pedersen Voll, F.A.; Corazza, M.L. Enhanced extraction of spent coffee grounds oil using high-pressure $\mathrm{CO}_{2}$ plus ethanol solvents. Ind. Crop. Prod. 2019, 141, 111723. [CrossRef]

12. Chemat, F.; Rombaut, N.; Sicaire, A.-G.; Meullemiestre, A.; Fabiano-Tixier, A.-S.; Abert-Vian, M. Ultrasound assisted extraction of food and natural products. Mechanisms, techniques, combinations, protocols and applications. A review. Ultrason. Sonochem. 2017, 34, 540-560. [CrossRef] [PubMed]

13. Wen, L.; Zhang, Z.; Sun, D.-W.; Sivagnanam, S.P.; Tiwari, B.K. Combination of emerging technologies for the extraction of bioactive compounds. Crit. Rev. Food Sci. Nutr. 2020, 60, 1826-1841. [CrossRef] [PubMed]

14. Farouk, B.; Hasan, N. Acoustic wave generation in near-critical supercritical fluids: Effects on mass transfer and extraction. J. Supercrit. Fluids 2015, 96, 200-210. [CrossRef] 
15. Shirsath, S.R.; Sonawane, S.H.; Gogate, P.R. Intensification of extraction of natural products using ultrasonic irradiations-A review of current status. Chem. Eng. Process. Proc. Intens. 2012, 53, 10-23. [CrossRef]

16. Heilmann, W. Decaffeination of Coffee. In Coffee: Recent Developments; Clarke, R.J., Vitzthum, O.G., Eds.; Blackwell Science Ltd.: London, UK, 2001; pp. 108-124.

17. Dassoff, E.S.; Li, Y.O. Mechanisms and effects of ultrasound-assisted supercritical $\mathrm{CO}_{2}$ extraction. Trends Food Sci. Technol. 2019, 86, 492-501. [CrossRef]

18. Riera, E.; Blanco, A.; García, J.; Benedito, J.; Mulet, A.; Gallego-Juárez, J.A. High-power ultrasonic system for the enhancement of mass transfer in super-critical $\mathrm{CO}_{2}$ extraction processes. Phys. Proced. 2010, 3, 141-146. [CrossRef]

19. Saldana, M.D.A.; Mohamed, R.S.; Baer, M.G.; Mazzafera, P. Extraction of purine alkaloids from mate (Ilex paraguariensis) using supercritical $\mathrm{CO}_{2}$. J. Agric. Food Chem. 1999, 47, 3804-3808. [CrossRef]

20. Rodríguez, Ó.; Ortuño, C.; Simal, S.; Benedito, J.; Femenia, A.; Rosselló, C. Acoustically assisted supercritical $\mathrm{CO}_{2}$ extraction of cocoa butter: Effects on kinetics and quality. J. Supercrit. Fluids 2014, 94, 30-37.

21. Tang, W.Q.; Li, D.C.; Lv, Y.X.; Jiang, J.G. Extraction and removal of caffeine from green tea by ultrasonic-enhanced supercritical fluid. J. Food Sci. 2010, 75, C363-C368. [CrossRef]

22. Hu, A.; Zhao, S.; Liang, H.; Qiu, T.; Chen, G. Ultrasound assisted supercritical fluid extraction of oil and coixenolide from adlay seed. Ultrason. Sonochem. 2007, 14, 219-224. [CrossRef]

23. Balachandran, S.; Kentish, S.E.; Mawson, R.; Ashokkumar, M. Ultrasonic en- hancement of the supercritical extraction from ginger. Ultrason. Sonochem. 2006, 13, 471-479. [CrossRef] [PubMed]

(C) 2020 by the authors. Licensee MDPI, Basel, Switzerland. This article is an open access article distributed under the terms and conditions of the Creative Commons Attribution (CC BY) license (http://creativecommons.org/licenses/by/4.0/). 